\title{
Morphometric Study of Human Adult Occipital Condyle, Hypoglossal Canal and Foramen Magnum in Dry Skull of Modern Egyptians
}

\author{
Shimaa Anter Farid*, Islam Omar Abdel Fattah \\ Department of Human Anatomy and Embryology, Faculty of Medicine, Suez Canal University, Ismailia, Egypt \\ Email address: \\ shimaa_ant@hotmail.com (S. A. Farid) \\ *Corresponding author \\ To cite this article: \\ Shimaa Anter Farid, Islam Omar Abdel Fattah. Morphometric Study of Human Adult Occipital Condyle, Hypoglossal Canal and Foramen \\ Magnum in Dry Skull of Modern Egyptians. International Journal of Clinical and Developmental Anatomy. Vol. 4, No. 1, 2018 , pp. 19-26. \\ doi: $10.11648 / j . i j c d a .20180401 .13$
}

Received: January 10, 2018; Accepted: February 1, 2018; Published: March 2, 2018

\begin{abstract}
The present study investigated analyze some morphometric data about occipital condyles (OCs), hypoglossal canals (HCs) and foramen magnum (FM) for safety transcondylar surgical approach, and to compare the Egyptian skull measurements with that of the other races. A total of 75 dry skulls of unknown sex which were randomly chosen from the archives of Department of Human Anatomy and Embryology, Faculty of Medicine, Suez Canal University were used with exclusion of the extremely deformed or damaged. The parameters were measured by digital Vernier calipers with $0.01 \mathrm{~mm}$ precision and a protractor. Statistical analysis of data - one way analysis of variance- was done using unpaired Student's t-test. Results indicated no statistical significant differences between the right and left sides of measured parameters. The morphometric analysis of the OC established that mean width \& length was larger $(14.8$ \& $22.9 \mathrm{~mm})$ in Egyptian population when compared to other races. According to the parameters of the HCs, the mean length of right and left ones were $11.84 \mathrm{~mm}$ and $11.8 \mathrm{~mm}$ respectively, while their mean angles with the sagittal plane were found to be $31.8^{\circ}$ and $31.6^{\circ}$ respectively. The mean diameter of the intracranial end of the right $\mathrm{HC}$ was $6.24 \mathrm{~mm}$ and of the left one was $6.04 \mathrm{~mm}$, on the other hand, the mean diameters of the extracranial ends were $6.18 \mathrm{~mm}$ and $6.04 \mathrm{~mm}$ respectively. Regarding the parameters of FM, the mean length and width were $35 \mathrm{~mm}$ and $29.4 \mathrm{~mm}$ respectively. On the other hand, the mean distance of right mastoid process to the nearest point of FM was $34.72 \mathrm{~mm}$, while the left one located at a mean distance of $35.2 \mathrm{~mm}$ from FM. $40 \%$ of skulls studied exhibited an ovoid foramen magnum as the foramen magnum index was $>1.2$ but $60 \%$ of our samples were $<1.2$ which were asymmetrical in shape. We conclude that careful radiological analysis of the craniocervical junction is required before surgery to prevent inadvertent complications such as hemorrhage, atlantooccipital instability and injury to major structures passing through foramen magnum. Our outcomes will be useful for safe surgery in craniocervical region in Egypt.
\end{abstract}

Keywords: Craniocervical Junction, Foramen Magnum, Occipital Condyles, Hypoglossal Canal, Morphometry and Transcondylar Approach

\section{Introduction}

The craniocervical junction $(\mathrm{CVJ})$ is defined as the occiput, atlas, and axis. It includes the area between the clivus to the second cervical vertebra and bounded laterally by jugular foramen (JF), occipital condyle (OC) and the hypoglossal canal (HC) [1]. This region mainly houses medulla oblongata, cervicomedullary junction, upper cervical part of spinal cord, multiple cranial nerves, and many important blood and lymphatic vessels that supply the head and neck. In addition to that, it contains 2 joints: the atlantooccipital and the atlantoaxial joints [2-3].

The morphology of $\mathrm{OC}$ is unique as it shares in formation of the craniovertebral joint permitting flexion and extension of the skull [4-5]. Just above and inside this $\mathrm{OC}, \mathrm{HC}$ is found. On the other hand, FM is found at the center of the skull base giving a passage for many vital structures such as the meninges, medulla oblongata, roots of the accessory 
nerve and vertebral arteries [6-7]. The study of the anatomy of these structures in clinical pathology and surgery justifies the implementation of new techniques for approaches at this region [8]. Due to its sensitive location, tumors located in the CVJ still have great challenges during their surgical resection. Although these tumors represent only about 5 percent of spinal tumors and only about 1 percent of all intracranial tumors, their resection is extremely difficult [9]. A number of surgical access routes of this region are currently available including transcondylar, supracondylar, and other lateral surgical approaches [10]. Conventional anatomy and surgery textbooks do not describe the anatomical variations in the OCs. Many such anomalies can be encountered incidentally [11].

So the objectives of this study are to analyze some morphometric data about OCs, HCs and FM for safety transcondylar surgical approach, and to compare the
Egyptian skull measurements with that of the other races, in addition.

\section{Materials and Methods}

\subsection{Material}

The present study included 75 dry skulls of unknown sex. These skulls were randomly chosen from the archives of Department of Human Anatomy and Embryology, Faculty of Medicine, Suez Canal University, with exclusion of the extremely deformed or damaged skulls.

\subsection{Equipment}

The used equipment was digital Vernier calipers with 0.01 $\mathrm{mm}$ precision (Jiahe dial caliper, Hong Kong) and a protractor "Figures $1 \mathrm{~A}$ and 1B".

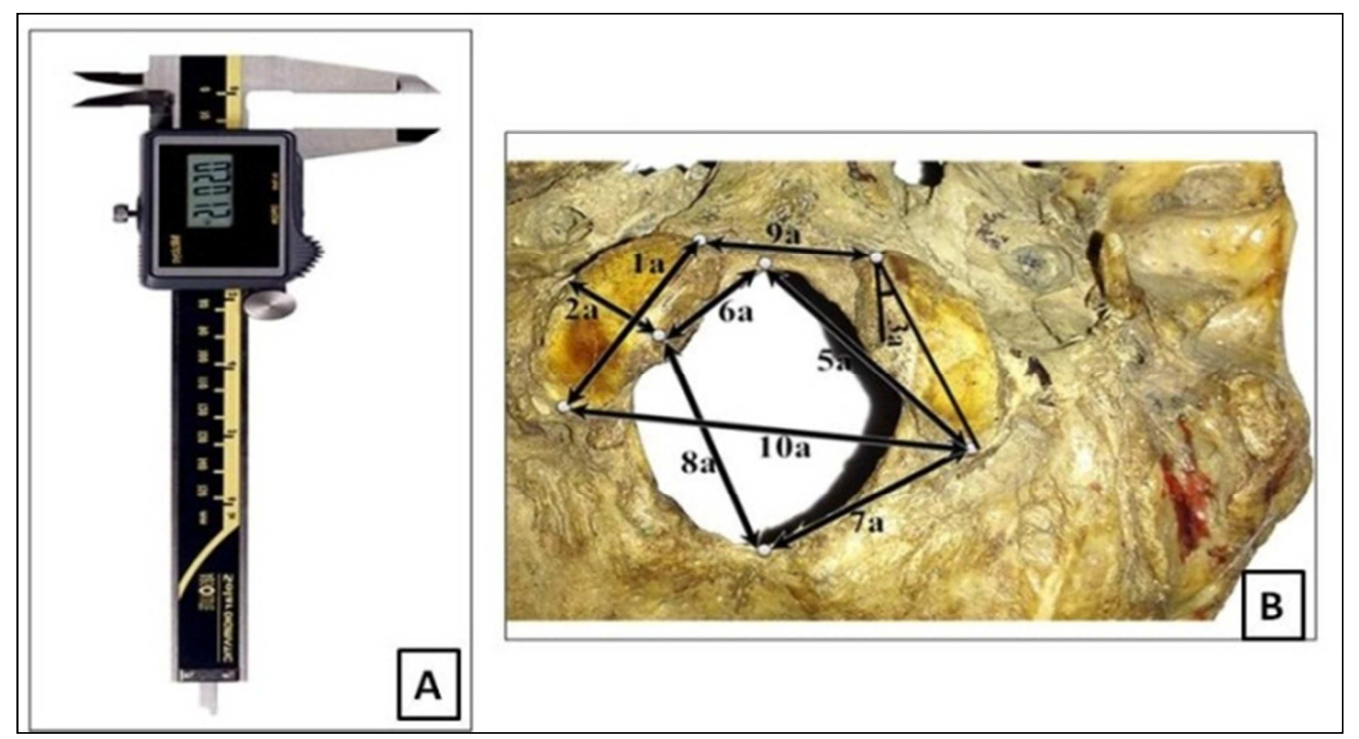

Figure 1. (A) Digital Vernier calipers. (B) Measurements of multiple parameters taken using digital Vernier calipers.

\subsection{The Measured Parameters Included the Following}

It included length, width, distances, angles and indices related to the OCs (right and left), HCs (right and left) and FM "Tables 1, 2 and 3".

Table 1. The measured parameters of OCs.

\begin{tabular}{|c|c|c|}
\hline Number & Parameter & Unit \\
\hline 1a & Length & $\mathrm{mm}$ \\
\hline $2 \mathrm{a}$ & Width & $\mathrm{mm}$ \\
\hline $3 a$ & Sagittal condylar angle & Degrees \\
\hline $4 \mathrm{a}$ & $\begin{array}{l}\text { Overriding distance of the medial border of OC } \\
\text { onto the FM, on each side }\end{array}$ & $\mathrm{mm}$ \\
\hline $5 \mathrm{a}$ & $\begin{array}{l}\text { Distances from posterior end of } \mathrm{OC} \text { to the basion, } \\
\text { on each side }\end{array}$ & $\mathrm{mm}$ \\
\hline $6 a$ & $\begin{array}{l}\text { Distances from midpoint of the medial border of } \\
\text { OC to the basion, on each side }\end{array}$ & $\mathrm{mm}$ \\
\hline $7 \mathrm{a}$ & $\begin{array}{l}\text { Distances from posterior end of OC to the } \\
\text { opisthion, on each side }\end{array}$ & $\mathrm{mm}$ \\
\hline $8 \mathrm{a}$ & $\begin{array}{l}\text { Distances from midpoint of the medial border of } \\
\text { OC to the opisthion, on each side }\end{array}$ & $\mathrm{mm}$ \\
\hline $9 \mathrm{a}$ & Anterior intercondylar distance (AICD) & $\mathrm{mm}$ \\
\hline $10 \mathrm{a}$ & Posterior intercondylar distance (PICD) & $\mathrm{mm}$ \\
\hline
\end{tabular}

Table 2. The measured parameters of HCs.

\begin{tabular}{|c|c|c|}
\hline Number & Parameter & Unit \\
\hline $1 b$ & Total length & $\mathrm{mm}$ \\
\hline $2 b$ & Angle of the $\mathrm{HC}$ to the sagittal plane & Degrees \\
\hline $3 b$ & Diameter of the intracranial end & $\mathrm{mm}$ \\
\hline $4 b$ & Diameter of the extracranial end & $\mathrm{mm}$ \\
\hline $5 b$ & Distance of the intracranial end of $\mathrm{HC}$ to the JF & $\mathrm{mm}$ \\
\hline $6 b$ & $\begin{array}{l}\text { Distance of the intracranial end of } \mathrm{HC} \text { to the posterior } \\
\text { margin of OC }\end{array}$ & $\mathrm{mm}$ \\
\hline $7 b$ & Distance between intracranial end of $\mathrm{HC}$ and basion & $\mathrm{mm}$ \\
\hline $8 b$ & $\begin{array}{l}\text { Distance between intracranial end of } \mathrm{HC} \text { and } \\
\text { opisthion }\end{array}$ & $\mathrm{mm}$ \\
\hline $9 \mathrm{~b}$ & Distance of the extracranial end of $\mathrm{HC}$ to the JF & $\mathrm{mm}$ \\
\hline \multicolumn{3}{|c|}{ Table 3. The measured parameters of FM. } \\
\hline Number & Parameter & Unit \\
\hline $1 \mathrm{c}$ & Maximum length (anteroposterior diameter) & $\mathrm{mm}$ \\
\hline $2 \mathrm{c}$ & Maximum width (transverse diameter) & $\mathrm{mm}$ \\
\hline $3 \mathrm{c}$ & Index of FM according to Muthukumar et al. & - \\
\hline $4 c$ & $\begin{array}{l}\text { The minimum distance between FM and the inner } \\
\text { aspect of the mastoid process, on each side }\end{array}$ & $\mathrm{mm}$ \\
\hline
\end{tabular}




\subsection{Index of Foramen Magnum}

Foramen magnum index was calculated using the following equation: Index of $F M=F M$ length $/ F M$ width. If
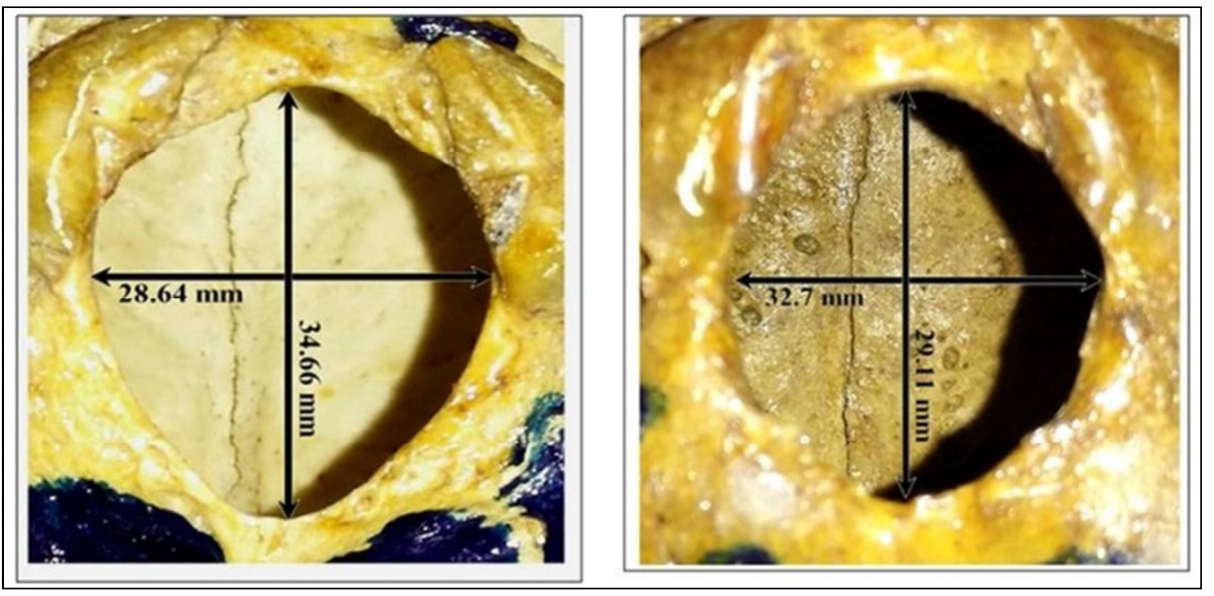

Figure 2. Measurement of foramen index.

\subsection{Statistical Analysis}

All data was expressed as mean \pm standard deviation (SD) and the level of statistical significance was performed using unpaired Student's t-test [13]. A P-value $<0.05$ was considered as a statistical significant difference. All statistical analyses were analysed using the SPSS software (16.0; SPSS, Inc. Chicago, IL, USA).

\section{Results}

All parameters of the paired structures showed no statistical significant difference between the right and left sides.

\subsection{Occipital Condyles}

As shown in table 4 and concerning the parameter of the right and left OCs, their mean length and width were found to the index was $\geq 1.2$, the foramen was considered oval in shape, while if it was $<1.2$, the foramen was regarded as asymmetrical "Figure 2" [12].

be $22.9 \mathrm{~mm}$ (right) and $23.2 \mathrm{~mm}$ (left) for the length, and $14.8 \mathrm{~mm}$ (right) and $15 \mathrm{~mm}$ (left) for the width. On the other hand, the mean of the right and left sagittal condylar angles was found to be $35.7^{\circ}$ and $33.36^{\circ}$ respectively.

Regarding the distance of overriding of the OCs on the FM, our samples showed that the mean of these distances were $6.22 \mathrm{~mm}$ for the right $\mathrm{OC}$ and $7.3 \mathrm{~mm}$ for the left one. On the other hand, the posterior end of the right OC located at a mean distance from the basion by $27.25 \mathrm{~mm}$ and from the opisthion by $27.1 \mathrm{~mm}$, while for the left side these distances were $27.93 \mathrm{~mm}$ and $27.7 \mathrm{~mm}$ respectively. The midpoint of medial end of right $\mathrm{OC}$ showed a mean distance of $16 \mathrm{~mm}$ from the basion and $29.78 \mathrm{~mm}$ from the opisthion, while for the left side these distances were $15.78 \mathrm{~mm}$ and $30.26 \mathrm{~mm}$ respectively. The mean AICD was $18.97 \mathrm{~mm}$, while the posterior one was $38.39 \mathrm{~mm}$ "Table 4".

Table 4. Parameters of OCs.

\begin{tabular}{|c|c|c|c|c|c|c|}
\hline \multirow{2}{*}{ Parameters } & \multicolumn{3}{|l|}{ Right } & \multicolumn{3}{|l|}{ Left } \\
\hline & Mean & Range & P value & Mean & Range & Pvalue \\
\hline Length (mm) & $22.9 \pm 2.8$ & 10.3 & 0.022 & $23.2 \pm 3$ & 12 & 0.022 \\
\hline Width (mm) & $14.8 \pm 2.3$ & 9.54 & 0.034 & $15 \pm 2.5$ & 11 & 0.042 \\
\hline Sagittal condylar angle (degree) & $35.7 \pm 12.1$ & 45 & 0.033 & $33.36 \pm 11$ & 45 & 0.023 \\
\hline Overriding distance of OC onto the FM (mm) & $6.22 \pm 1.8$ & 6.5 & 0.026 & $7.3 \pm 1.6$ & 6.80 & 0.003 \\
\hline Distances from posterior end of $\mathrm{OC}$ to the basion $(\mathrm{mm})$ & $27.25 \pm 2.4$ & 9.4 & 0.032 & $27.93 \pm 2.53$ & 9.36 & 0.042 \\
\hline Distances from posterior end of $\mathrm{OC}$ to the opisthion $(\mathrm{mm})$ & $27.1 \pm 2.7$ & 9.39 & 0.033 & $27.7 \pm 3.2$ & 11.45 & 0.025 \\
\hline Distances from midpoint of the medial border of OC to the basion (mm) & $16 \pm 2.3$ & 7.5 & 0.012 & $15.78 \pm 2.3$ & 9.2 & 0.034 \\
\hline Distances from midpoint of the medial border of OC to the opisthion $(\mathrm{mm})$ & $29.78 \pm 2.7$ & 12.1 & 0.027 & $30.26 \pm 2.8$ & 12.41 & 0.017 \\
\hline \multirow{2}{*}{$\operatorname{AICD}(\mathrm{mm})$} & \multicolumn{2}{|l|}{ Mean } & \multicolumn{2}{|l|}{ Range } & \multicolumn{2}{|l|}{$P$ value } \\
\hline & \multicolumn{2}{|l|}{$18.97 \pm 2.03$} & \multicolumn{2}{|l|}{6.84} & \multicolumn{2}{|l|}{0.023} \\
\hline PICD (mm) & \multicolumn{2}{|l|}{$38.39 \pm 4.4$} & \multicolumn{2}{|l|}{16.40} & \multicolumn{2}{|l|}{0.027} \\
\hline
\end{tabular}

\subsection{Hypoglossal Canal}

According to the parameters of the HCs, as shown in table 5 , the mean length of right and left ones were $11.84 \mathrm{~mm}$ and
$11.8 \mathrm{~mm}$ respectively, while their mean angles with the sagittal plane were found to be $31.8^{\circ}$ and $31.6^{\circ}$ respectively. The mean diameter of the intracranial end of the right $\mathrm{HC}$ was $6.24 \mathrm{~mm}$ and that of the left one was $6.04 \mathrm{~mm}$, on the other hand, the mean diameters of the extracranial ends were 
$6.18 \mathrm{~mm}$ and $6.04 \mathrm{~mm}$ respectively. The mean distance between the intracranial end and the JF was $12.2 \mathrm{~mm}$ for the right side and $12.7 \mathrm{~mm}$ for the left side, while the mean distance between these ends to the posterior margin of the OC were $12.66 \mathrm{~mm}$ and $13.17 \mathrm{~mm}$ respectively. The intracranial end also found to lie at a mean distance of 35.1 $\mathrm{mm}$ from opisthion and $15.8 \mathrm{~mm}$ from basion for the right side and the mean of these distances were $35.6 \mathrm{~mm}$ and 15.9 $\mathrm{mm}$ for the left side respectively. On the other hand, the extracranial end of the right $\mathrm{HC}$ found to lie at a mean distance from the right $\mathrm{JF}$ of $9.3 \mathrm{~mm}$ and $9.48 \mathrm{~mm}$ for the left side "Table 5".

Table 5. Parameters of HCs.

\begin{tabular}{|c|c|c|c|c|c|c|}
\hline \multirow{2}{*}{ Parameters } & \multicolumn{3}{|l|}{ Right } & \multicolumn{3}{|l|}{ Left } \\
\hline & Mean & Range & P value & Mean & Range & P value \\
\hline Length (mm) & $11.84 \pm 2.56$ & 9.68 & 0.033 & $11.8 \pm 2.4$ & 10.30 & 0.0173 \\
\hline Angle of the $\mathrm{HC}$ to the sagittal plane (degrees) & $14.8 \pm 2.3$ & 9.54 & 0.034 & $15 \pm 2.5$ & 11 & 0.042 \\
\hline Diameter of the intracranial end (mm) & $6.24 \pm 0.31$ & 6.9 & 0.039 & $6.04 \pm 1.2$ & 5.14 & 0.04 \\
\hline Diameter of the extracranial end (mm) & $6.18 \pm 1.2$ & 5.5 & 0.04 & $6.04 \pm 1.2$ & 5.14 & 0.04 \\
\hline Distance of the intracranial end of $\mathrm{HC}$ to the JF (mm) & $12.2 \pm 2$ & 6.74 & 0.04 & $12.7 \pm 2.3$ & 8.3 & 0.04 \\
\hline Distance between intracranial end of $\mathrm{HC}$ and basion (mm) & $15.8 \pm 2.5$ & 9.7 & 0.034 & $15.9 \pm 2.8$ & 11.6 & 0.035 \\
\hline Distance between intracranial end of $\mathrm{HC}$ and opisthion (mm) & $35.1 \pm 6.2$ & 26.09 & 0.032 & $35.6 \pm 6$ & 26.8 & 0.0211 \\
\hline Distance of the extracranial end of $\mathrm{HC}$ to the JF (mm) & $9.3 \pm 3.4$ & 11.3 & 0.021 & $9.48 \pm 3.2$ & 12.21 & 0.0234 \\
\hline
\end{tabular}

\subsection{Foramen Magnum}

About the parameters of FM, the mean length (anteroposterior diameter) and width (transverse diameter) were $35 \mathrm{~mm}$ and 29.4 $\mathrm{mm}$ respectively "Figure 3". On the other hand, the mean distance of right mastoid process to the nearest point of FM was
$34.72 \mathrm{~mm}$, while the mean of the left distance was $35.2 \mathrm{~mm}$ "Table 6". When the FM index was $\geq 1.2$, the foramen was found to be ovoid, $40 \%$ of skulls studied exhibited an ovoid FM, but $60 \%$ of our samples were $<1.2$ which were asymmetrical in shape "Table 7 and Figure 4".

Table 6. Parameters of FM.

\begin{tabular}{|c|c|c|c|c|c|c|}
\hline \multirow{2}{*}{ Parameters } & \multicolumn{3}{|l|}{ Right } & \multicolumn{3}{|l|}{ Left } \\
\hline & Mean & Range & P value & Mean & Range & P value \\
\hline Distances between mastoid process and FM & $34.72 \pm 2.9$ & 10.43 & 0.028 & $35.2 \pm 3$ & 11.3 & 0.043 \\
\hline \multirow{2}{*}{ Length of FM (mm) (anteroposterior diameter) } & Mean & & Range & & $P$ value & \\
\hline & $35 \pm 2.8$ & & 12.4 & & 0.021 & \\
\hline Width of FM (mm) (transverse diameter) & $29.4 \pm 2.9$ & & 11 & & 0.034 & \\
\hline
\end{tabular}

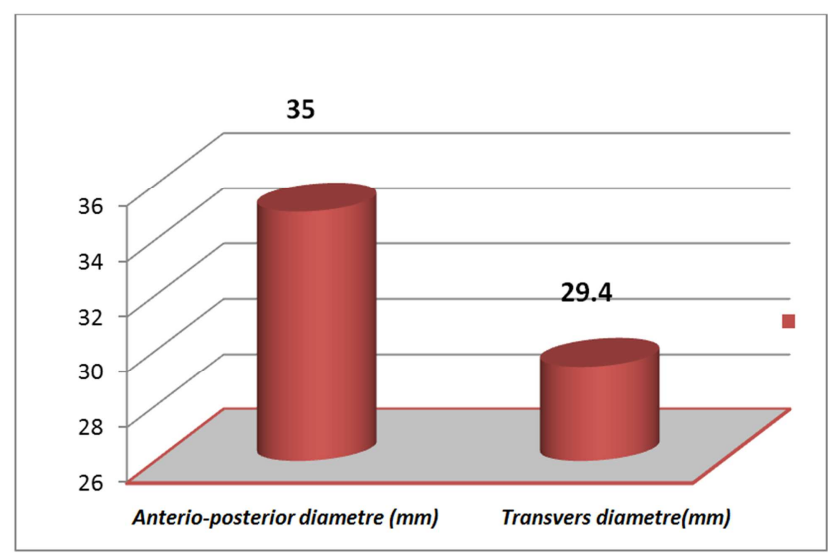

Figure 3. The Anteroposterior and transverse diameter of FM.

Table 7. Frequency and percentage of FM index.

\begin{tabular}{llll}
\hline FM index & Frequency & Percentage & Shape \\
\hline$<1.2$ & 45 & $60 \%$ & Asymmetrical \\
$\geq 1.2$ & 30 & $40 \%$ & Ovoid \\
Total & 75 & $100 \%$ & \\
\hline
\end{tabular}

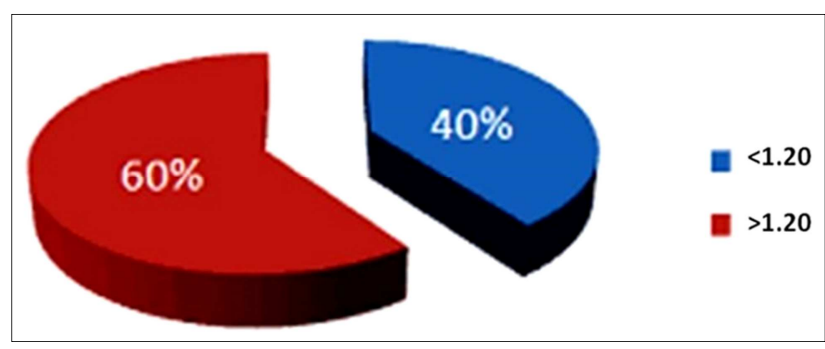

Figure 4. Percentage of FM index.

\section{Discussion}

The current direction in modern neurosurgeries has a minimally invasive surgery [8]. So, neurosurgeons must be aware of the anatomy of the CVJ and the different surgical approaches for its lesions. These lesions may be congenital or acquired in form of tumors, bony defects, traumatic injuries or inflammatory pathologies [2]. The important anatomical knowledge for condylar drilling should be paid toward the relationships between the OCs, FM and HCs as well as the vertebral arteries [8]. Thus the high mortality and morbidity rates may be due to defective information about this region 
[6]. Nevertheless, our results showed differences as well as similarities with different races that should be considered as well as our measurements showed differences among the individuals of the same race and also differences between the right and left sides of the same individual.

\subsection{Occipital Condyles}

The OC length, width, angle with the sagittal plane, distance of its overriding on the FM and its relationship to $\mathrm{HC}$ are important preoperative information about $\mathrm{OC}$ that should be known. For example, the intercondylar distances and the OC sagittal angle are important to be considered before determining the bone quantity that should be removed during resection of the posterior one third of the OC. Thus, less bone should be removed in case of wide intercondylar distances, while more bone removal with a smaller intercondylar distances [7-8].

In the current study the mean length and width of the OCs results were $22.9 \mathrm{~mm}$ and $14.8 \mathrm{~mm}$ for the right one, and $23.2 \mathrm{~mm}$ and $15 \mathrm{~mm}$ for the left one respectively. These results were nearly agreed with the findings of Fetouh [14] who found that the mean length was $23.5 \mathrm{~mm}$ and $23.75 \mathrm{~mm}$ and the mean width was $13.58 \mathrm{~mm}$ and 13.62 for the right and left $\mathrm{OC}$ respectively in the Egyptian skulls. Also the study of Aziz [15] on Egyptian skulls showed a very similar results with our results about OC length $(22.5 \mathrm{~mm}$ and 22.75 $\mathrm{mm}$ for the right and left OC respectively), but their results about OC width were lower than our measurements (11.5 $\mathrm{mm}$ for the right and left ones).

Our measurement results were greater than that of Sudanese population as shown by Salih [16] who found that the mean length of the OCs were $21.2 \mathrm{~mm}$ for the right one and $20.1 \mathrm{~mm}$ for the left one while the mean width was 13.1 $\mathrm{mm}$ and $12.4 \mathrm{~mm}$ for the right and left ones respectively. On the other hand, Muthukuma $\mathrm{r}[12]$ showed that the mean length and width of OCs were nearer to our results in Indian dry skulls that were $23.6 \mathrm{~mm}$ and $14.7 \mathrm{~mm}$ respectively. While, Naderi [17] found that the mean length and width of OCs of skulls of Turkish people were $23.4 \mathrm{~mm}$ and $10.6 \mathrm{~mm}$ respectively. Their results were nearly in accordance of our results for the length but smaller for width. In contrast, the Iranian dry skulls showed much lower dimensions, according to Bayat [18] who found that the mean length of the OCs was $19.43 \mathrm{~mm}$ and $19.28 \mathrm{~mm}$ for the right and left ones respectively, while the mean of their width was $9.21 \mathrm{~mm}$ and $9.4 \mathrm{~mm}$ respectively.

In the present study, the mean overriding distances of the OCs on the FM were $6.22 \mathrm{~mm}$ for the right side and $7.3 \mathrm{~mm}$ for the left side. These results were nearly correspondent to the research of Pereira [19] who found that the mean overriding distance were $7.01 \mathrm{~mm}$ and $6.95 \mathrm{~mm}$ for the right and left sides respectively which is nearly concomitant with our measurements on the Egyptian skulls. In the current study, the mean sagittal angle of the right $\mathrm{OC}$ was $35.7^{\circ}$ and that of the left one was $33.36^{\circ}$, while the mean AICD was $18.97 \mathrm{~mm}$ and the posterior one was $38.39 \mathrm{~mm}$. Aziz [15] showed that the mean AICD in Egyptian skulls was $22.6 \mathrm{~mm}$, while the posterior one was $42.45 \mathrm{~mm}$ which were much greater distances than our results.

According to Indian skulls, Saluja [20] found that the mean right condylar sagittal angle was $41.10^{\circ}$ and the left one was $44.04^{\circ}$ which indicates higher condylar angles in Indians than in Egyptians. On the other hand, they also demonstrated in their study that the mean AICD was 17.81 $\mathrm{mm}$ which was nearly similar to our results. However, both Kalthur [21] and Naderi [17] found the mean AICDs of Indians and Turks were the same $(21 \mathrm{~mm})$ which is greater than in Egyptians and greatly lower in Iranians $(15.39 \mathrm{~mm})$ according to Bayat [18].

The distances between the basion or opisthion and posterior borders of the OCs demonstrate the surgical exposure width in case of suboccipital craniotomy, while that between the basion or opisthion and the OCs midpoints are important to know the surgical exposure width in case of 50 percent condylar drilling [8]. Our results showed that the mean distances between the basion to posterior border of the OCs were $27.25 \mathrm{~mm}$ and $27.93 \mathrm{~mm}$ for the right and left side respectively which were nearly similar to the Egyptian dimensions shown by Fetouh [14] (27.38 mm and $27.97 \mathrm{~mm}$ respectively). On the other hand, Aziz [15]showed that the mean of these distances in the Egyptian skulls were 28.35 $\mathrm{mm}$ for the right side and $28.9 \mathrm{~mm}$ for the left one that were slightly different from our results.

Nevertheless, the results were nearly agreed with that of Indian skulls demonstrated by Saluja [20] (28.16 mm and $26.93 \mathrm{~mm}$ respectively), but slightly higher than the measurements of Pereira [19] (26.07 $\mathrm{mm}$ and $25.75 \mathrm{~mm}$ respectively). Also Pereira showed that the mean distances between the basion to the midpoint of the right OC was 14.87 $\mathrm{mm}$ and for the left one was $14.63 \mathrm{~mm}$ that were higher than the Egyptian measurements shown by the present study (16 $\mathrm{mm}$ and $15.78 \mathrm{~mm}$ respectively). The current study showed that the mean distances from the opisthion to the posterior border of OCs were $27.1 \mathrm{~mm}$ and $27.7 \mathrm{~mm}$ for the right and left sides respectively that was nearly similar to results of Fetouh [14] who showed that these distances were $27.87 \mathrm{~mm}$ for the right side and $27.94 \mathrm{~mm}$ for the left one in Egyptians.

Also Aziz [15] found that the mean distances were 27.87 $\mathrm{mm}$ for the right side and $27.94 \mathrm{~mm}$ for the left one in the Egyptian skulls that were also very similar to our results. Our results were also nearly similar in Indians as shown by Saluja [20] and Kalthur [21] who showed that the mean of these distances were $26.17 \mathrm{~mm}$ and $27.8 \mathrm{~mm}$ for the right side and $26.48 \mathrm{~mm}$ and $28 \mathrm{~mm}$ for the left side respectively. Naderi [17] showed slightly lower results in Turks than in Egyptians that were $26.7 \mathrm{~mm}$ for the right side and $26.2 \mathrm{~mm}$ for the left one. In the present study, the mean distances between the opisthion to the midpoint of OCs were $29.78 \mathrm{~mm}$ for the right side and $30.26 \mathrm{~mm}$ for the left one which were slightly greater than in Indians as shown by Pereira [19] $(28.78 \mathrm{~mm}$ and $28.32 \mathrm{~mm}$ respectively).

\subsection{Hypoglossal Canal}

In case of transcondylar access of $\mathrm{CVJ}$, the precise 
relationship between $\mathrm{OC}$ and the overlying $\mathrm{HC}$, and the possible HC depth and direction all are important to be known [22]. In addition, this anatomical knowledge is important to be understood in case of resection of a tumor located close to or within the $\mathrm{HC}$ [7]. In the present study the mean length of the right $\mathrm{HC}$ was $11.84 \mathrm{~mm}$ and of the left one was $11.8 \mathrm{~mm}$ which were less than in Indians as shown by Muthukumar [12] who found that the mean HC length of both sides was $12.6 \mathrm{~mm}$ that was nearly similar to measurements of Indian skulls demonstrated by Vinay [6] (12.5 $\mathrm{mm}$ for the right $\mathrm{HC}$ and $12.6 \mathrm{~mm}$ for the left one). Nevertheless, Turkish skulls showed that the length of the HC was less than in Egyptians in the study of Kizilkanat [7] ( $9.8 \mathrm{~mm}$ for the right one and $10 \mathrm{~mm}$ for the left one). On the other hand, in our study the mean $\mathrm{HC}$ sagittal angles were $14.8^{\circ}$ for the right side and $15^{\circ}$ for the left one. These angles were much less than shown in Indian skulls in the study of Muthukumar [12] who found that the mean HC sagittal angle of both sides was $49^{\circ}$.

In the current study, Egyptian skulls showed intracranial end mean diameters of the HCs of $6.24 \mathrm{~mm}$ and $6.04 \mathrm{~mm}$, and extracranial end mean diameters of $6.18 \mathrm{~mm}$ and $6.04 \mathrm{~mm}$ for the right and left ones respectively. These diameters were slightly less than Indian skulls, as found by Muthukumar [12] who had mean intracranial end diameter for both sides of 7.2 $\mathrm{mm}$ and extracranial one of $7.9 \mathrm{~mm}$. On the other hand, Turkish skulls in the study of Kizilkanat [7] had nearer diameters to the Egyptians that were $6.4 \mathrm{~mm}$ and $6.5 \mathrm{~mm}$ for the right and left intracranial end diameters respectively and $6.6 \mathrm{~mm}$ and $6.5 \mathrm{~mm}$ for the right and left extracranial end diameters respectively. Parvindokht [22] found that Iranian dry skulls had much less diameters than Egyptian ones. Iranian skulls showed mean intracranial end diameter for both sides of $2.99 \mathrm{~mm}$ and a mean extracranial one of $3.17 \mathrm{~mm}$.

The mean distances of the intracranial end of $\mathrm{HC}$ to the JF in the present study were $12.2 \mathrm{~mm}$ for the right side and 12.7 $\mathrm{mm}$ for the left one that were less than shown by Kizilkanat [7] who showed distances of $13.1 \mathrm{~mm}$ and $13.5 \mathrm{~mm}$ for the right and left sides respectively in the Turkish skulls. While Muthukumar [12] showed that Indian skulls have less distance (of $10 \mathrm{~mm}$ ) than the Egyptian ones. Egyptian skulls in our study showed mean distances between the intracranial end of $\mathrm{HC}$ to the posterior margin of $\mathrm{OC}$ of $12.66 \mathrm{~mm}$ for the right side and $13.17 \mathrm{~mm}$ for the left one. These results were slightly greater than the results of the Turkish skulls shown by Kizilkanat [7] (12.4 mm for the right side and $12.2 \mathrm{~mm}$ for the left one) and also greater than in Iranian and Indian ones, as shown by Parvindokht [22] and Muthukumar [12] (11.43 $\mathrm{mm}$ and $12.2 \mathrm{~mm}$ respectively).

The distances between the HC and basion, as shown by Kizilkanat [7] in Turkish, were $16.6 \mathrm{~mm}$ and $16.4 \mathrm{~mm}$ for the right and left sides respectively that were greater than in Egyptians in our study (15.8 $\mathrm{mm}$ and $15.9 \mathrm{~mm}$ respectively). While, in the same Turkish study, the distances between the HCs and opisthion were lower than our study (29 mm vs 35.1 $\mathrm{mm}$ and $29.1 \mathrm{~mm}$ vs $35.6 \mathrm{~mm}$ for the right and left sides respectively). On the other hand, Iranian skulls, as shown by
Parvindokht [22], had less distance between the HCs and basion $(12.5 \mathrm{~mm})$, and between the HCs and opisthion (33.88 $\mathrm{mm})$.

In the current study, the mean distances of the extracranial end of $\mathrm{HC}$ to the JF were $9.3 \mathrm{~mm}$ for the right side and 9.48 $\mathrm{mm}$ for the left one that were greater than in Turkish skulls ( $8.6 \mathrm{~mm}$ and $8.2 \mathrm{~mm}$ for the right and left sides respectively) as shown by Kizilkanat. and much greater than in Indians (5 $\mathrm{mm})$ as shown by Muthukumar [7, 12].

\subsection{Foramen Magnum}

In the present study, the mean length and width of FM were $35 \mathrm{~mm}$ and $29.4 \mathrm{~mm}$ respectively. Sayed [23] found that the mean FM lengths were $36.22 \mathrm{~mm}$ in males and $32.99 \mathrm{~mm}$ in females, and mean FM width in males was $30.04 \mathrm{~mm}$ and in females was $26.96 \mathrm{~mm}$ in the Egyptian skulls. Their ranges of results were nearly agreed to our measurements. Also Aziz [15] found that the mean length of FM in Egyptian dry skull was $35.94 \mathrm{~mm}$ that was slightly greater than our results. However by CT scan studies on Egyptian skulls, as done by Abdel-Karim [24] FM dimensions were greater than our study with mean lengths of $42.17 \mathrm{~mm}$ for males and 38.75 $\mathrm{mm}$ for females, and mean widths of $33.98 \mathrm{~mm}$ for males and $31.38 \mathrm{~mm}$ for females. These different data may be due to different measurement methods.

These FM dimensions in Egyptians were nearly the same compared to the Sudanese skulls $(34.1 \mathrm{~mm}$ and $29.4 \mathrm{~mm}$ for the length and width respectively), as shown by Salih [16] on Turkish skulls that showed nearly similar FM dimensions as found by Cirpan [25] (34.38 $\mathrm{mm}$ and $28.95 \mathrm{~mm}$ for the length and width respectively). On the other hand, Nagwani [26] demonstrated that Indian skulls had little different FM dimensions (34.68 $\mathrm{mm}$ for the length and $27.24 \mathrm{~mm}$ for the width).

There are various types of FM based on its shape. It can be oval or asymmetrical shapes (egg, round, tetragonal, pentagonal, hexagonal and irregular). In the present study oval shaped FM was found to be more frequent, which was similar to the results obtained by a study done by Radhakrisha [27] on the Indian skulls. In the study done by Murshed and Chethan [28-29] the foramina magna were more frequently round in Turkish and Indian skulls respectively. In the present study the mean FM index was found to be $1.11 \mathrm{~mm}$, with range being minimum 1.0 to maximum being 1.61 with standard deviation of 0.1 out of 75 specimens. Out of 75 skulls $40 \%$ exhibited ovoid FM. Muthukumar [12] also determined the shape of FM using FM index and found that $46 \%$ of specimens has FM index of $\geq 1.2$ and considered as oval in Indians. Kizilkanat [7] found that the mean FM index was 1.2 in Turkish skulls. Also in a Turkish study done by Avic [30] 58\% of specimens were showing ovoid FM. The shape and morphological variations of FM are important in neurological interpretation. In an ovoid type of the FM, the surgeon may find it difficult to explore the anterior portion of the FM.

Limitations of Our Study: The main limitation of the current study is that the age and gender of the skulls were 
unknown which may be an important factor affecting our metric measurements. Also further radiological techniques could be used to get more relationship between the osteological and radiological measurements. In addition, pathological factors that may affect the skull dimensions and relationships were not considered in our study. These limitations can be considered in further studies.

\section{Conclusion}

In the present study, an effort has been made for adequate morphometric measures of some parameters for $\mathrm{HCs}$, OCs and FM. These parameters should be taken into consideration during posterior and lateral approaches to the CVJ by the neurosurgeons and orthopaedicians. The preoperative radiological evaluation is important for achieving surgical success along with thorough anatomical knowledge and surgical experience. Hence, it can be concluded that careful radiological analysis of the $\mathrm{CVJ}$ is required before surgery to prevent inadvertent complications such as hemorrhage, atlantooccipital instability and injury to major structures passing through FM. Our outcomes will be useful for safe surgery in craniocervical region in Egypt.

\section{References}

[1] B. Ayoub. (2011). The far lateral approach for intra-dural anteriorly situated tumours at the craniovertebral Junction. Turk. Neurosurg. 21(4): 494-498.

[2] D. Refai, J. H. Shin, C. Iannotti, and E. C. Benzel. (2010). Dorsal approaches to intradural extramedullary tumors of the craniovertebral junction. J. of Craniovertebr. Junction and Spine; 1(1): 49-54.

[3] R. S. Tubbs, J. D. Hallock, V. Radcliff, R. P. Naftel, M. Mortazavi, M. M.Shoja, M. Loukas, and A. A. Cohen-Gadol. (2011). Ligaments of the craniocervical junction: a review. J. Neurosurg. Spine; 14(6): 697-709.

[4] R. Verma, S. Kumar, A. M. Rai, I. Mansoor, and R. D. Mehra. (2016). The anatomical perspective of human occipital condyle in relation to the hypoglossal canal, condylar canal, and jugular foramen and its surgical significance. $J$. Craniovertebr. Junction Spine; 7(4): 243-249.

[5] A. J. Lopez, J. K. Scheer, K. E. Leibl, Z. A. Smith, B. J. Dlouhy, and N. S. Dahdaleh. (2015). Anatomy and biomechanics of the craniovertebral junction. Neurosurg. Focus; 38(4): 1-8.

[6] K. Vinay, V. Swathi, M. Y. Denia, and K. S. Sachin. (2016) Morphometric study of hypoglossal canal of occipital bone in dry skulls of South India. Int. J. Anat. Res.; 4(4): 3016-3019.

[7] E. D. Kizilkanat, N. Boyan, R. Soames, and O. Oguz. (2006) Morphometry of the hypoglossal canal, occipital condyle, and foramen magnum. Neurosurg. Q.; 16(3): 121-125.

[8] G. Agnihotri, D. Mahajan, and A. Sheth. (2014). An anatomical perspective of human occipital condyles and foramen magnum with neurosurgical correlates. Jemds; 3(17): 4479-4503.
[9] S. Khaoroptham, P. Jittapiromsak, R. Siwanuwatn, and K. Chantra. (2007) The outcome of surgical treatment for tumors of the craniocervical junction. J. Med. Assoc. Thai.; 90(7): 1450-1457.

[10] D. Lang, G. Neil-Dwyer, and F. Iannotti. (1993). The suboccipital transcondylar approach to the clivus and craniocervical junction for ventrally placed pathology at and above the foramen magnum. Acta neurochirurgica 125(1): 132-137.

[11] S. Das, R. Suri, and V. Kapur. (2006). Unusual occipital condyles of the skull: an osteological study with clinical implications. Sao Paulo Med J.; 124(5): 278-279.

[12] N. Muthukumar, R. Swaminathan, G. Venkatesh, and S. Bhanumathy. (2005). A morphometric analysis of the foramen magnum region as it relates to the transcondylar approach. Acta Neurochir.; 147(8): 889-895.

[13] A. K. Tale, P. R. Kulkarni, S. I. Shaikh, and S. S. Fupare. (2016) Morphometric study of the occipital condyle and its surgical importance. Int. J. Anat. Res.; 4(1): 1802-1805.

[14] F. A. Fetouh, and A. M. Awadalla. (2009). Morphometric analysis of the occipital condyle and its surgical implications in transcondylar approach. The pan arab neurosurgery society; 15 .

[15] J. N. S. Aziz, and M. Youakim. (2016). Morphological study of the foramen magnum and occipital condyle and its surgical implications in transcondylar approach. Libyan J. Med. Res.; 10(1): 70-82.

[16] A. M. Salih, C. E. Ayad, and E. A. Abdalla. (2014). Characterization of occipital condyles in Sudanese using computerized tomography. Glo. Adv. Res. J. Med. Med. Sci.; 3(12): 437-444.

[17] S. Naderi, E. Korman, G. Çıtak, M. Güvençer, C. Arman, M. Şenoğlu, S. Tetik, and M. N. Arda. (2005). Morphometric analysis of human occipital condyle. Clin. Neurol. Neurosurg.; 107(3): 191-199.

[18] P. Bayat, M. Bagheri, A. Ghanbari, and A. Raoofi. (2014). Characterization of occipital condyle and comparison of its dimensions with head and foramen magnum circumferences in dry skulls of Iran. Int. j. morphol; 32(2): 444-448.

[19] G. P. Pereira, A. Lopes, R. Santos, L. Duarte, A. Piva, and G. Pozzobon. (2012). Morphometric analysis related to the transcondylar approach in dry skulls and computed tomography. Int. j. morphol.; 30(2): 399-404.

[20] S. Saluja, S. S. Das, and N. Vasudeva. (2016). Morphometric analysis of the occipital condyle and its surgical importance. JCDR 10(11): AC01-AC04.

[21] S. G. Kalthur, S. Padmashali, S. C. Gupta, and A. S. Dsouza. (2014) Anatomic study of the occipital condyle and its surgical implications in transcondylar approach. J. Craniovertebr. Junction Spine; 5(2): 71-77.

[22] B. Parvindokht, D. M. Reza, and B. Saeid, (2015). Morphometric analysis of hypoglossal canal of the occipital bone in Iranian dry skulls. J. Craniovertebr. Junction Spine; 6(3): 111-114.

[23] W. M. Sayed, and I. F. Gaballah. (2015). A study of the dimensions of both the foramen magnum and occipital condyles in modern Egyptians and their use in sex determination. Egyptian J. of Anatomy; 38(1): 29-42. 
[24] R. Abdel-Karim, A. M. Housseini, and R. Hashish. (2015). Adult sex estimation using three-dimensional volume Rendering multislice computed tomography of the foramen magnum and occipital condyles: a study in Egyptian population. Int. J. Adv. Res.; 3: 1212-1215.

[25] S. Cirpan, G. N. Yonguc, N. G. Mas, F. Aksu, and A. O. Magden, (2016). Morphological and morphometric analysis of foramen magnum: an anatomical aspect. J. Craniofac. Surg.; 27(6): 1576-1578.

[26] M. Nagwani, A. Rani, and A. Rani. (2016). A morphometric and comparative study of foramen magnum in North Indian population. Journal of the Anatomical Society of India; 65: 1115 .

[27] S. Radhakrishna, C. Shivarama, A. Ramakrishna, and B. Bhagya, (2012). Morphometric analysis of foramen magnum for sex determination in South Indian population. Nitte Uni. J. Health Sci.; 2(1): 20-22.

[28] K. A. Murshed, A. E. Çiçekcibaşi, and I. Tuncer. (2003). Morphometric evaluation of the foramen magnum and variations in its shape: a study on computerized tomographic images of normal adults. Turk. J. Med. Sci.; 33(5): 301-306.

[29] P. Chethan, K. G. Prakash, B. V. Murlimanju, K. U. Prashanth,, L. V. Prabhu, V. V. Saralaya, A. Krishnamurthy, M. S. Somesh, and C. G. Kumar. (2012). Morphological analysis and morphometry of the foramen magnum: an anatomical investigation. Turk. neurosurg.; 22(4): 416-419.

[30] E. Avci, A. Dagtekin, A. H. Ozturk, E. Kara, N. C. Ozturk, K. Uluc, E. Akture, and M. K. Baskaya. (2011). Anatomical variations of the foramen magnum, occipital condyle and jugular tubercle. Turk. Neurosurg.; 21(2): 181-190. 